University of Nebraska - Lincoln

DigitalCommons@University of Nebraska - Lincoln

1998

Structure of the Avian Oviduct With Emphasis on Sperm Storage in Poultry

Murray R. Bakst

United States Department of Agriculture

Follow this and additional works at: https://digitalcommons.unl.edu/usdaarsfacpub

Part of the Agricultural Science Commons

Bakst, Murray R., "Structure of the Avian Oviduct With Emphasis on Sperm Storage in Poultry" (1998). Publications from USDA-ARS / UNL Faculty. 623.

https://digitalcommons.unl.edu/usdaarsfacpub/623

This Article is brought to you for free and open access by the U.S. Department of Agriculture: Agricultural Research Service, Lincoln, Nebraska at DigitalCommons@University of Nebraska - Lincoln. It has been accepted for inclusion in Publications from USDA-ARS / UNL Faculty by an authorized administrator of DigitalCommons@University of Nebraska - Lincoln. 


\title{
Structure of the Avian Oviduct With Emphasis on Sperm Storage in Poultry
}

\author{
MURRAY R. BAKST* \\ U.S. Department of Agriculture, Agricultural Research Service, Germplasm \\ and Gamete Physiology Laboratory, Livestock and Poultry Sciences Institute, \\ Beltsville, Maryland 20705
}

\begin{abstract}
The macroanatomy, histology, and fine structure of the avian oviduct is reviewed and related to its role in fertile egg production. The avian oviduct functions as a biological assembly line, beginning sequentially with the deposition of the albumen around the fertilized or unfertilized ovum, then the shell membrane, and lastly, the shell, all within $25 \mathrm{hr}$ of ovulation. While in transit through the oviduct, the fertilized ovum progresses to the pre-gastrulation stage of development. J. Exp. Zool. 282:618-626, 1998. @ 1998 Wiley-Liss, Inc. ${ }^{\dagger}$
\end{abstract}

Each structural component of the laid egg, except for the yolk (the hen's ovum) is derived from the oviduct. When released from the ovary, the ovulated ovum is gathered into the ostium by the action of the fimbriated region of the infundibulum. If sperm are present, the ovum may be fertilized. Regardless, the ovum traverses the oviduct and accrues the albumen in the magnum, the shell membrane in the isthmus, and the hard shell in the uterus. The most caudal segment, the vagina, contributes the cuticle to the egg prior to oviposition and also serves as a conduit between the uterus and cloaca. The time elapsed from ovulation to oviposition is about $25 \mathrm{hr}$. If the laid egg was fertilized, the blastoderm, which consists of about 60,000 cells in the chicken and 30,000 cells in the turkey, is in the pre-gastrulation stage.

In order to fertilize a nearly daily succession of ova, which amounts to 2 to 7 eggs per week, sperm are slowly but continuously released from the oviductal sperm storage sites in the caudal end of the oviduct and are transported to the site of fertilization at the cranial end of the oviduct. The precise mechanisms which regulate these complex processes remain to be elucidated. However, since the 1980s we have begun to better understand the mechanisms which regulate sperm storage and selection in the avian oviduct (see Bakst et al., '94).

This paper will examine the structure and function of the avian oviduct relative to its role in producing a normal fertilized egg. In addition to providing a brief review of the pertinent literature, new observations and accompanying speculation on the significance of these observations will

(c) 1998 WI LEY-LISS, INC. 'This article is a US Government work and, as such, is in the public domain of the United States of America. be presented. Unless otherwise stated, descriptions will be limited to Galliformes, specifically, commercial chickens and turkeys.

\section{OVIDUCT STRUCTURE General anatomy}

The oviduct in the mature hen in egg production (Fig. 1) consists of five morphologically and functionally distinct segments with a total length of $80-85 \mathrm{~cm}$ in the chicken and $90-95 \mathrm{~cm}$ in the turkey. In each segment but the uterus (sometimes referred to as the shell gland), the luminal mucosa of the oviduct consists of distinct longitudinal folds (plicae) which vary in height, coloration, and volume both before and after the passage of an egg mass (Figs. 2, 3). In the uterus, this orientation is difficult to discern as the mucosa form spade-shaped leaflets which collectively appear to have a pleated, transverse orientation.

The luminal mucosa of the oviduct consists of nonciliated secretory cells (often referred to as goblet cells) and ciliated cells. Ciliated cells may or may not possess secretory granules in their apical cytoplasm (Makita et al., '73). The histochemical and immunocytochemical staining properties (including that of lectins) of the surface epithelium suggest that the secretory cells in each segment elaborate different products (Aitken, '71; Kami and Yasuda, '84; Yamamoto et al., '85; Bakst, '87).

*Correspondence to: M.R. Bakst, BIdg. 262, BARC-East, Beltsville, MD 20705 


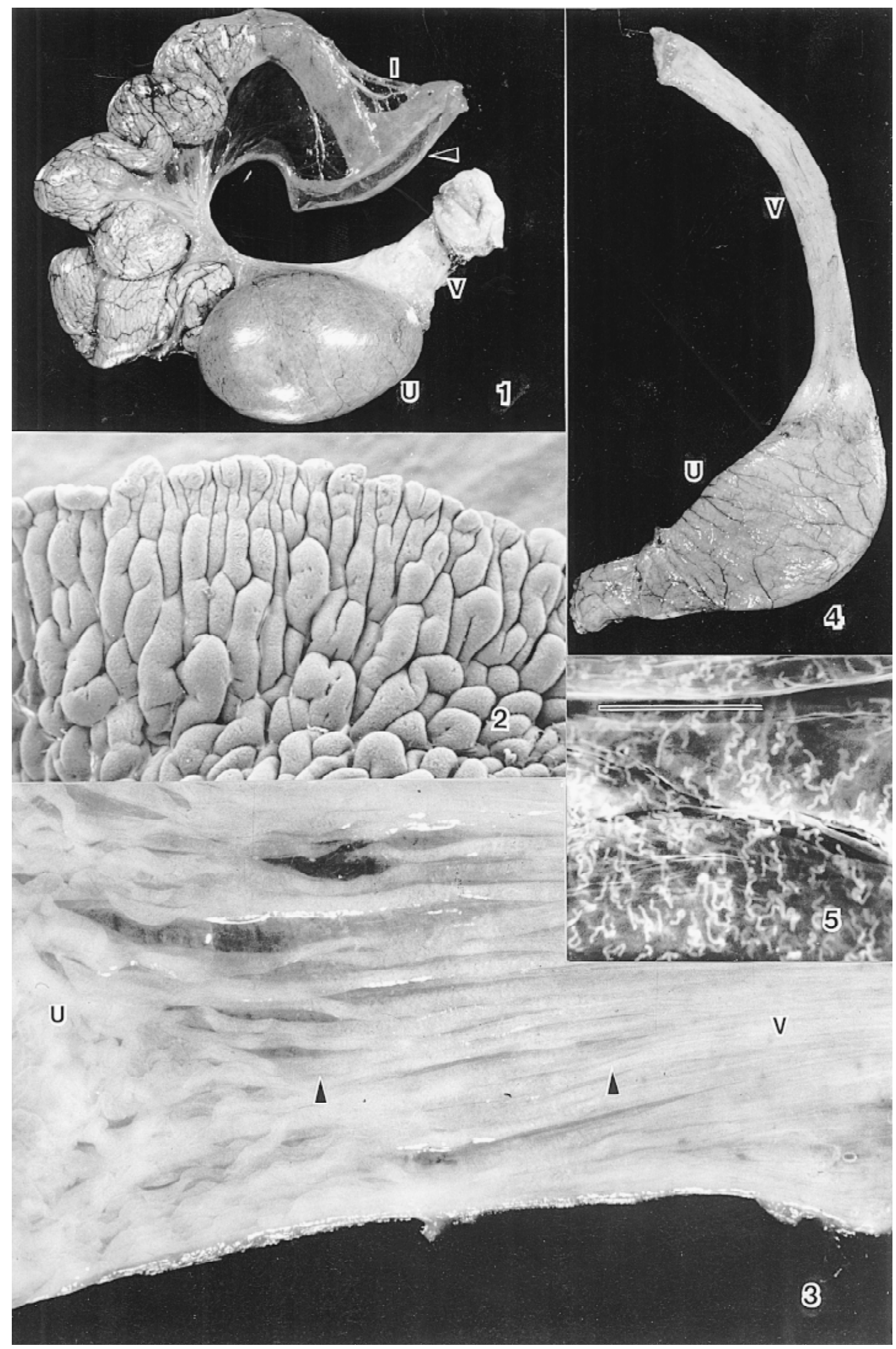

Figures 1-5. (Caption on next page.) 
The fimbriated region of the infundibulum (also referred to as the funnel portion of the infundibulum) (Fig. 2) and the vagina are densely populated with ciliated cells. The abovarian direction (away from the ovary) of the cilia beat may be partially responsible for the ovum entering the ostium of the infundibulum (F ujii et al., '81). The ratio of ciliated to nonciliated secretory cells is greater toward the luminal surface of the folds. Nonciliated cells predominate in the basal aspects of the folds and are found exclusively in the subepithelial tubular glands throughout the oviduct.

The structures forming the egg mass enveloping the ovum are derived primarily, but not exclusively, from the subepithelial tubular glands located from the mid-section of the infundibulum through the uterus. These exocrine glands fully differentiate shortly after the onset of egg production and appear to vary in complexity and volume. All have a well-defined transition between the surface (luminal) epithelial cells and the epithelium forming the tubular gland.

Located in the uterovaginal junction (UVJ) (Figs. 3, 4), which is a narrow band at the anterior end of the vagina, are the primary sperm storage sites in the oviduct, the sperm-storage tubules (SST). Based on histological (light and electron microscopy) and histochemical observations, these specialized subepithelial tubular glands are capable of only limited secretory activity (Bakst, '87). This characteristic may be one of the factors that contribute to the successful storage of sperm in the SST over a succession of daily ovulatory cydes.

The loose connective tissue in the lamina propria is populated with lymphocytes, plasma cells, macrophages, fibroblasts, and mast cells. Nerve, collagen, and elastin fibers are also discernible

Figures appear on p. 619.

Fig. 1. The turkey oviduct with a hard-shelled egg in the uterus (U). The fimbriated region (arrowhead) of the infundibulum (I) is evident. The vagina (V) is coiled and enveloped in a connective tissue casing.

Fig. 2. A scanning electron micrograph of the mucosal surface of the rim of the fimbria. The complex array of mucosal folds is lined with a ciliated epithelium. (Bar $=500 \mu \mathrm{m})$

Fig. 3. The vaginal mucosa $(V)$ is composed of numerous longitudinally oriented plicae which merge with the more complex folds of the uterine mucosa (U). A 1.5-cm band (between arrowheads) at the anterior end of the vagina contains the SST, which are barely discernible here.

Fig. 4. The uterus (U) and vagina (V) are observed after the connective tissue surrounding the vagina is removed. The uterovaginal junction is evident as a slightly bulbous area.

Fig. 5. Stereomicroscopy of the anterior end of the vagina reveals the coiled SST, most exceeding $250 \mu \mathrm{m}$ in length. (Bar $=1 \mathrm{~mm}$ ) and easily visualized in the segments in which subepithelial tubular invaginations are absent or less densely distributed. Intraepithelial Iymphocytes, particularly in females in egg production for several months, are prevalent in the mucosal surface and SST epithelia. These, as well as plasma cells in the lamina propria, are IgG positive (Bakst, '87).

\section{OVIDUCTAL SPERM STORAGE SITES Vagina}

A more detailed overview of the vagina is warranted considering its multiple roles in sperm selection, storage, and transport (see Bakst et al., '94). The primary folds of the vaginal mucosa, which lack exocrine-type tubular glands, are divided into smaller parallel secondary and tertiary folds (Fig. 3). Scanning el ectron microscopy (SEM) of the vagina's luminal surface reveal longitudinally oriented, parallel tracts densely covered by a ciliated epithelium.

In hens in egg production, the UVJ is fully discernible after dissecting away the connective tissue binding the vagina in a tightly coiled configuration (compare Fig. 1 with Fig. 4). When the stripped-down vagina is slit longitudinally, its luminal mucosa is exposed and the contrasting morphology and coloration of the uterine leaflets to the longitudinal folds of the vagina are evident. The SST generally are localized within the anterior 1 to $3 \mathrm{~cm}$ of the vagina (Fig. 3) and are easily visualized at this point by stereomicroscopy (Fig. 5).

The SST are derived from invaginations of the oviduct's surface epithelium (Bakst, '92). The SST epithelium consists of nonciliated columnar cells,

Fig. 6. A similar preparation to Fig. 5 showing the subepithelial tubular glands of the distal infundibulum.

Fig. 7. A similar preparation to Figs. 5 and 6 showing the subepithelial tubular glands of the distal infundibulum and the magnal subepithelial tubular glands.

Fig. 8. A bright field micrograph of the distal infundibuIum highlighting the subepithelial tubular glands. The transition from a ciliated epithelium to a nonciliated secretory epithelium is observed (arrowhead). (Bar $=80 \mu \mathrm{m}$ )

Fig. 9. A bright field micrograph of the subepithelial tubular glands of the distal infundibulum. The denser appearing glands are magnal subepithelial tubular glands.

Fig. 10. A DIC micrograph of an unfixed squash preparation of distal infundibulum revealing a single capillary (arrowhead) adjacent to a subepithelial tubular gland. (Bar = $40 \mu \mathrm{m})$

Fig. 11. Adjusting the focal plane through the epithelial mucosa surface of the distal infundibulum reveals openings to the subepithelial tubular glands surrounded by epithelial cells. 


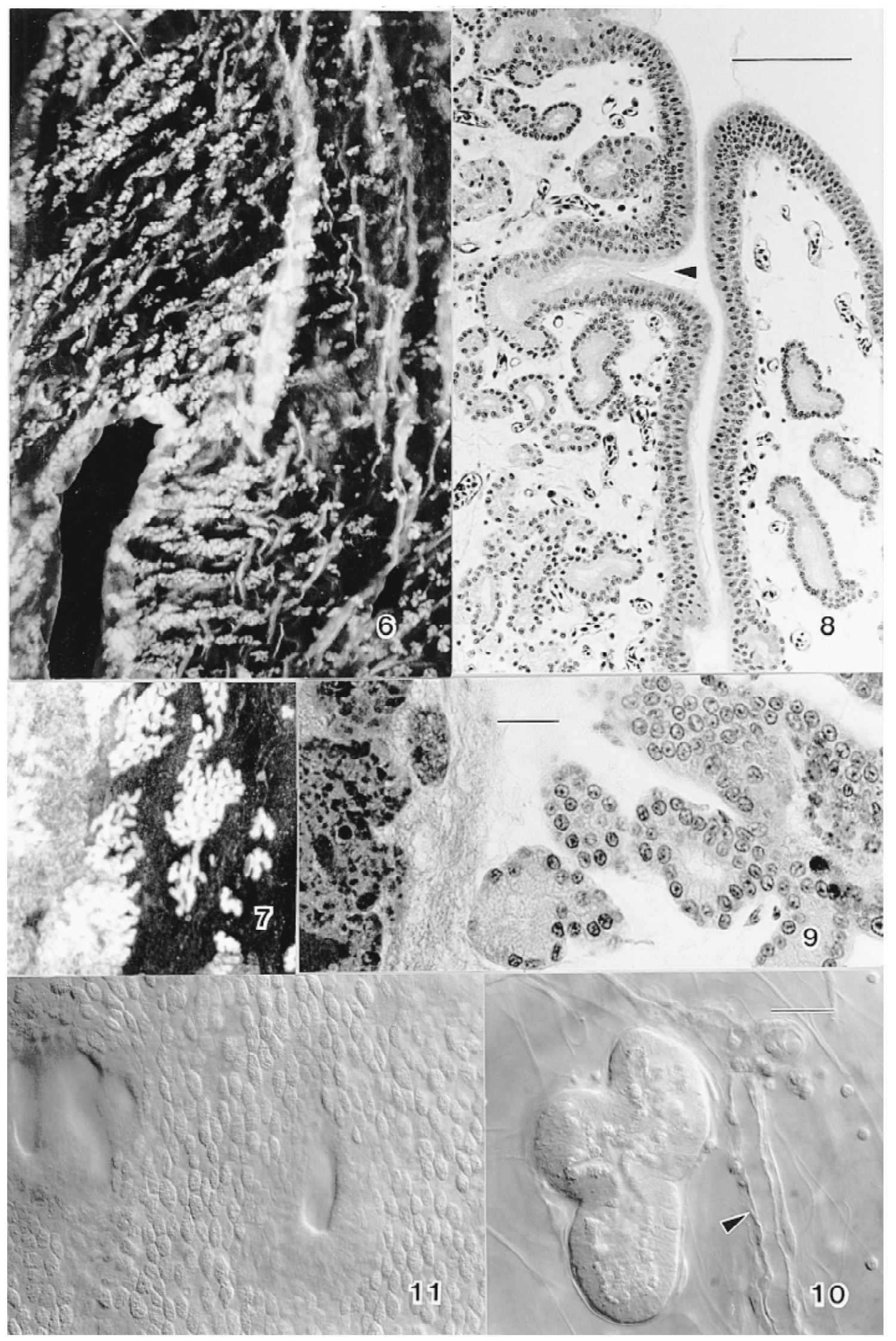

Figures 6-11. 
which in the turkey are about $20 \mu \mathrm{m}$ in height, and in the chicken about $15 \mu \mathrm{m}$ in height (Mero and Ogasawara, '70). The intracellular lipid distribution and content may vary between and within species. Mitochondria are most prevalent in the basal area of the cell. While lacking an abundance of secretory granules, the tips of surface microvilli, which approach about $1 \mu \mathrm{m}$ in height, are occasionally observed to bleb, possibly an indication of limited exocytotic activity. While such blebs may be an artifact of preparing the specimen for transmission electron microscopy, their consistency suggests exocytotic activity, possibly representing a source of lipid or protein for use by resident sperm (Bakst, '93).

Recent work performed in our laboratory (V. Akuffo, S. Freedman, and M. Bakst, unpublished) has provided some additional insight into the epithelial cell structure of the SST. Using an F-actin-specific immunofluorescence probe, we were able to visualize by confocal microscopy a discrete, dense microfilament network in the immediate vicinity of the microvillous border. This network, which is clearly evident in transmission electron micrographs, may be involved in the release of resident sperm from the SST.

The lateral faces of SST epithelial cells form complex interdigitations, which at the apical surface are further characterized by tight and intermediate junctions. It is possible to visual ize these "terminal bars" in the lumen of individual SST in unfixed squash preparations of UVJ mucosa viewed by differential interference contrast (DIC) microscopy. Desmosomes are distributed along the remaining length of the lateral walls. Myoepithelial cells are not observed around any aspect of the SST. Contrary to previous authors (Gilbert et al., '68), we (Freedman, Akuffo, and Bakst, unpublished) have demonstrated the immunocytochemical localization of nerve fibers in close association with the outer connective tissue surrounding the individual SST. In addition, neurons have also been observed within $100 \mu \mathrm{m}$ of SST. Whether there are also specialized endocrine or peptide secreting cells in the oviduct epithelium has yet to be determined.

\section{Infundibulum}

The most anterior segment of the oviduct is the infundibulum (Fig. 1). It has been subdivided into three functionally and morphologically distinct regions: the fimbriated region, which guides the ovulated ovum into the ostium of the infundibu- lum; the funnel region, which lacks subepithelial tubular glands, but is presumably the site where sperm first contact the recently ovulated ovum; and the chalaziferous region, which will be referred to here as the distal infundibulum (Aitken and J ohnston, '63; Aitken, '71; Gilbert, '79; Fujii et al., '81). The distal infundibulum is the "secondary" sperm-storage site in the oviduct (Van Drimmelen, '51; Fujii and Tamura, '63; Bakst, '81) and is characterized by subepithelial tubular glands (Figs. 6-14) which secrete an albumen-like material around the ovum (Bain and Hall, '69), referred to as the outer perivitelline layer. The outer perivitelline layer provides an additional fibrous protein investment around the ovum and, relative to the process of fertilization, prevents excessive sperm penetration of the ovum at the anterior end of the oviduct. It should be noted that while polyspermy is normal in birds, excessive sperm penetration of the germinal disc region leads to pathological polyspermy (Bakst and Howarth, '77), which results in early embryonic mortality. In the transition zone between the proximal magnum and the distal infundibulum, the tubular glands from each segment can be clearly viewed by phase contrast (Fig. 7) and bright field microscopy (Fig. 9).

Little is known of the mechanisms of sperm transport to and storage in the infundibulum.

Fig. 12. A dual DIC-fluorescence micrograph of a distal infundibular subepithelial tubular gland with a single fluorescing bisbenzimide stained sperm (arrowhead) in the lumen. Visualization of this sperm was possible only by reducing the DIC illumination. (Bar $=40 \mu \mathrm{m}$ )

Fig. 13. If a hen is inseminated with sperm stained with bisbenzimide immediately after oviposition, some of the distal infundibular subepithelial tubular glands become engorged with sperm. In this fluorescence micrograph, three of the four distal ends of the tubular glands are fluorescing brightly due to sperm accumulations. The fourth tubular, which is barely discernible, is evident in Fig. 14. Also note that the bisbenzimide has stained the nuclei (arrow) of the tubular gland epithelium with resident sperm. (Bar $=40 \mu \mathrm{m}$ )

Fig. 14. A DIC micrograph of the same subepithelial tubular glands observed in Fig. 13. While the epithelial nuclei are visible, only one sperm is observed (arrowhead). Secretory granules are also dearly evident in the apical portion of the epithelial cells forming the tubular glands. The arrow highlights the same nucleus highlighted in Fig. 13. (Bar $=40 \mu \mathrm{m}$ )

Fig. 15. A dual DIC-fluorescence micrograph of a single SST with numerous bisbenzimide stained sperm in its lumen. Connective tissue fibers are densely distributed around the SST. The arrow highlights a nucleus in a SST epithelial cell. (Bar $=50 \mu \mathrm{m})$

Fig. 16. In this fluorescence micrograph, the profile of another SST is observed with numerous bisbenzimide stained sperm in its lumen. 

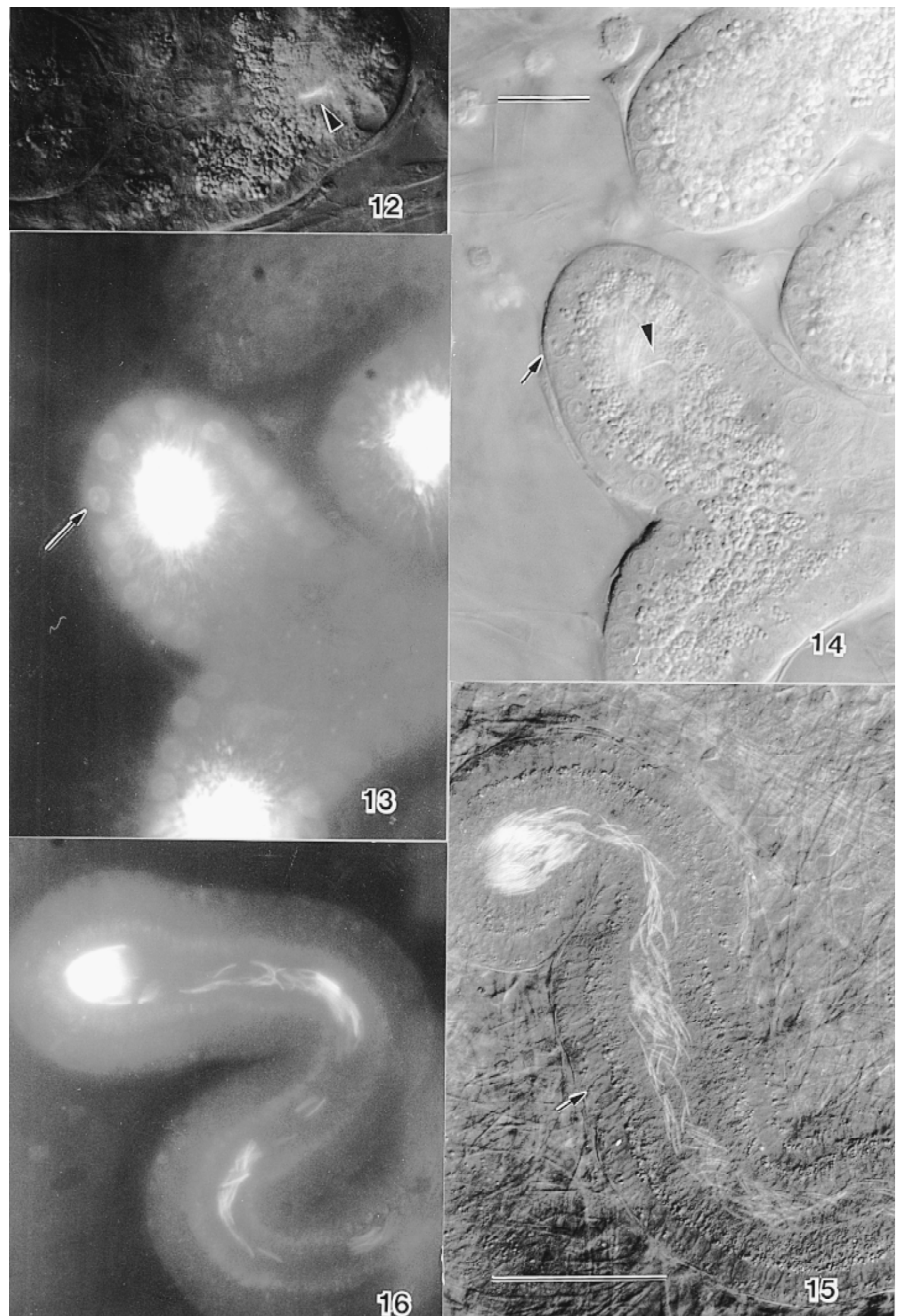

Figures 12-16. 
During the course of the daily ovulatory cycle sperm are slowly released from the SST and ascend to the distal infundibulum. Here they accrue in the tubular glands and are probably released with the ovum-induced distention of the mucosa combined with the active secretion of the albumen-like proteins.

Squash preparations viewed by phase contrast and DIC microscopy have been useful in developing a better understanding of the role of the infundibulum in sperm storage in turkeys (Bakst, '94) and other Galliformes. Using DIC on fresh mucosa, the beating pattern of the densely ciliated surface of the fimbria can be clearly observed. As the number of nonciliated cells increases in the funnel region, shallow bud-like invaginations of the surface epithelium begin to appear. These invaginations are composed of nonciliated cells which do not contain any appreciable amount of secretory material in their apical cytoplasm. Sperm were not observed in these invaginations. With the focal plane at the level of the surface epithelium, cross sections of polygonal cells with secretory granules (Fig. 11) or nuclei can be observed surrounding the openings to the tubular glands.

The surface topography changes little as one progresses toward the distal infundibulum. Budlike invaginations originating from the surface epithelium lining the distal infundibulum appear more voluminous and begin to branch (Fig. 8). The epithelium is composed of nonciliated cells with and without secretory granules in their apical cytoplasm. More caudally, in the transition region between the distal infundibulum and proximal magnum, the tubular glands increase in complexity and volume until individual tubular glands are no longer discernible (Figs. 7, 9). The epithelium forming these glands is clearly secretory, possessing abundant secretory granules in their apical cytoplasm.

Rarely were more than one sperm observed in the distal infundibular (Fig. 12) or magnal tubular glands (Fujii and Tamura, '63; Schindler et al., '67; Bakst, '94). However, if a hen is subject to artificial insemination (200 to 300 million sperm introduced into the distal vagina) immediately after oviposition, large numbers of sperm infiltrate the infundibular tubular glands (Figs. 13, 14) (Burke and Ogasawara, '69; Brillard, '90a,b; Bakst et al., '94) and the proximal $1 \mathrm{~cm}$ of the magnum (Fujii and Tamura, '63; Bobr et al., '64a,b; Schindler et al., '67; Bakst, '81, '83). A similar infiltration of the infundibulum with sperm follows intrauterine and/or intramagnal inseminations (Ogasawara et al., '66; Brillard, '90a,b). In such instances, the abnormally high population of sperm at the site of fertilization increases the possibility of pathological polyspermy and the high incidence of embryonic mortality.

\section{Recommended approaches to study of the hen's oviduct}

I have used a variety of approaches to characterize various aspects of oviductal anatomy and oviduct-sperm interactions in the hen. Routine light and electron microscopy provided fundamental histological information. However, there were limitations to these techniques, particularly when attempting to evaluate sperm distribution in the sperm storage sites in the UVJ and infundibulum.

I found the most useful and versatile procedure simply involved using a squash preparation of unfixed oviductal mucosa. I solated pieces of plicae (no larger than $3 \times 3 \mathrm{~mm}$ ) without the muscularis can be viewed by stereomicroscopy, phase contrast, or DIC microscopy. Compared to routinely stained histological sections, these procedures provide a much improved appreciation of the spacial distribution of the subepithelial tubular glands and SST with and without sperm in poultry (Bakst, '87, '92, '94; Bakst et al., '94) as well as in feral birds (Bakst and Bird, '87; Birkhead and Moller, '92).

Our ability to resolve resident sperm in the SST, infundibulum, and other areas of the oviduct is significantly improved if the hen is inseminated with sperm previously stained with nuclear fluorescent dye bisbenzimide (Hoechst 33342, Molecular Probes, Eugene, OR) (Bakst, '94). The sperm staining procedure is applicable to other avian species but preliminary work should be performed to optimize the staining procedure and evaluate the impact of the stain and staining procedure on sperm viability and subsequent fertility. With fresh turkey semen, the pooled sample is diluted to about 5 billion sperm per $\mathrm{ml}$ with poultry semen extender and thoroughly mixed. An equal volume of extender containing $120 \mu \mathrm{g}$ bisbenzimide per $\mathrm{ml}$ is added to the diluted semen and the mixture placed on a rotary shaker for $2 \mathrm{hr}$ at room temperature before insemination. This procedure minimizes the inimical effects of the bisbenzimide on hen fertility and egg hatchability while maximizing sperm fluorescence.

Dual DIC and fluorescence microscopy of squash preparations of oviductal mucosae revealed single 
sperm as well as dense accumulations of sperm residing in SST (Fig. 15) and infundibular tubular glands (Figs. 12, 14). Fluorescing sperm become more evident as the DIC light source is reduced or eliminated (Figs. 13, 16). Here again the investigator must be prepared to modify some established practices in order to optimize the viewing of oviductal sperm. For example, to view fluorescing sperm residing in the infundibular region, the DIC optics may have to be slightly modified. By sliding the DIC analyzer out of its proper position, an image is created which allows visualization of resident sperm in the voluminous infundibular tubular glands (Bakst, '94). This is particularly useful when large surface areas need to be evaluated to determine the presence or absence of sperm.

Other techniques have been developed and reviewed elsewhere which provide means to estimate the efficacy of oviductal sperm storage (Bakst et al., '94; Bakst and Cecil, '97). These procedures are based on estimating the number of sperm embedded in the outer perivitelline layer of the fresh laid egg or by estimating the number of holes (sites where penetrating sperm have hydrolyzed a path through the ovum's investment) present in the perivitelline layer overlying the germinal disc of a fresh laid egg.

To conclude, a better understanding of the physiological and molecular mechanisms of oviductal sperm selection and storage will provide the basis for improvements in the efficiency of poultry breeding. Furthermore, the same knowledge will aid in the development of improved technologies for the propagation of endangered birds and the preservation of their germplasm.

\section{LITERATURE CITED}

Aitken, R.N.C. (1971) The oviduct. In: Physiology and Biochemistry of the Domestic Fowl, Vol. 3. D.J . Bell and B.M. F reeman, eds. Academic Press, New York, pp. 1237-1289.

Aitken, R.N.C., and H.S. J ohnston (1963) Observations on the fine structure of the infundibulum of the avian oviduct. J . Anat. Lond., 97:87-89.

Bain, J.M., and J .M. Hall (1969) Observations on the development and structure of the vitelline membrane of the hen's egg: An electron microscope study. Aust. J . Biol. Sci., 22:653-656.

Bakst, M.R. (1983) Fate of turkey spermatozoa after intrainfundibular and intramagnal inseminations. J. Reprod. Fert., 67:315-317.

Bakst, M.R. (1987) Anatomical basis of sperm storage in the avian oviduct. Scanning Microsc., 1:1256-1266.

Bakst, M.R. (1992) Observations on the turkey oviductal sperm-storage tubule using differential interference contrast microscopy. J . Reprod. Fert., 95:877-883.

Bakst, M.R. (1993) Oviductal sperm storage in poultry. Reprod. Fert. Devel. 5:595-599.
Bakst, M.R. (1994) F ate of fluorescent stained sperm following insemination: New light on oviductal sperm transport and storage in the turkey. Biol. Reprod., 50: 987-992.

Bakst, M.R., and D.M. Bird (1987) Localization of oviductal sperm-storage tubules in the American Kestrel (Falco sparverius). The Auk, 104:321-324.

Bakst, M.R., and H. Cecil, eds. (1997) Artificial Insemination of Poultry: Procedures for the Collection, Evaluation, Storage, and Insemination of Semen. Poultry Science Assoc., Inc. Savoy, IL.

Bakst, M.R., and B. Howarth, J r. (1977) Hydrolysis of the hen's perivitelline layer by cock sperm in vitro. Biol. Reprod., 17:370-379.

Bakst, M.R., G.J . Wishart, and J .P. Brillard (1994) Oviductal sperm selection, transport, and storage in poultry. Poult. Sci. Rev., 5:117-143.

Birkhead, T.R., and A.P. Moller (1992) Sperm Competition in Birds: Evolutionary Causes and Consequences. Academic Press, New York.

Bobr, L.W., F.W. Lorenz, and F.X. Ogasawara (1964a) Distribution of spermatozoa in the oviduct and fertility in domestic birds. I. Residence sites of spermatozoa from fowl oviducts. J . Reprod. Fert., 8:39-47.

Bobr, L.W., F.X. Ogasawara, and F.W. Lorenz (1964b) Distribution of spermatozoa in the oviduct and fertility in domestic birds. II. Transport of spermatozoa in the fowl oviduct. J . Reprod. Fert., 8:49-58.

Brillard, J .P. (1990a) Migration of spermatozoa in the oviduct of hens following intramagnal and intra-abdominal insemination. Theriogenology, 33:1021-1027.

Brillard, J.P. (1990b) Stockage des spermatozoides dans I'oviducte chez les oiseaux: Approche morphologique, histologique et fonctionnelle. Reprod. Nutr. Dev., 30:161-174.

Burke, W.H., and F.X. Ogasawara (1969) Presence of spermatozoa in uterovaginal fluids of the hen at various stages of the ovulatory cycle. Poult. Sci., 48:408-413.

F ujii, S., and T. Tamura (1963) Location of sperms in oviduct of the domestic fowl with special reference to storage of sperms in the vaginal gland. J. Fac. Fish. Anim. Husb. Hiroshima Univ., 5:145-163.

Fujii, S., Y. Yoshimura, T. Okamoto, and T. Tamura (1981) The regional morphology of the infundibulum of the hen's oviduct with special reference to the mechanism of the engulfing of the ovulated ovum. J. Fac. Appl. Biol. Sci. Hiroshima Univ., 10:87-94.

Gilbert, A.B. (1979) Female genital organs. In: Form and Function in Birds, Vol. 1. A.S. King, and J . McLelland, eds. Academic Press, New York, pp. 237-360.

Gilbert, A.B., M.E. Reynolds, and F.W. Lorenz (1968) Distribution of spermatozoa in the oviduct and fertility in domestic birds. VII. Innervation and vascular supply of the uterovaginal sperm-host glands of the domestic hen. J . Reprod. Fert., 17:305-310.

Kami, K., and K. Yasuda (1984) Immunoelectron microscopical demonstration of endogenous avidin in secretory granules of the hen oviduct mucosa: A preliminary study. Histochem. J ., 16:835-842.

Makita, T., S. Kiwaki, and E.B. Sandborn (1973) Secretion granules in the ciliated cells of the avian oviduct. Arch. Histol. J ap., 35:209-224.

Mero, K.N., and F.X. Ogasawara (1970) Dimensions of uterovaginal sperm-storage tubules of the chicken and their possible significance in sperm release. Poult. Sci., 49:13041308. 
Ogasawara, F.X., F.W. Lorenz, and L.W. Bobr (1966) Distribution of spermatozoa in the oviduct and fertility in domestic hens. III. Intrauterine insemination from low fecundity cocks. J . Reprod. Fert., 11:33-41.

Schindler, H., E. Ben-David, S. Hurwitz, and O. Kempenich (1967) The relation of spermatozoa to the glandular tissue in the storage sites in the hen oviduct. Poult. Sci., 46:1462-1471.

Van Drimmelen, G.C. (1951) Artificial insemination of birds by the intraperitoneal route. A study in sex physiology of pigeons and fowls with reports upon a modified technique of semen collection, and a new technique of insemination, and observations on the spermatozoa in the genital organs of the fowl hen. Onderstepoort J . Vet. Res., Suppl. No. 1:3-212.

Yamamoto, T., H. Ozawa, H. Nagai (1985) Histochemical studies of Ca-ATPase, succinate and NAD+dependent isocitrate dehydrogenases in the shell gland of laying J apanese quails with special reference to calcium-transporting cells. Histochemistry, 83:221-226. 